Method Patients were randomised to HOT or HOT-HMV if they had persistent hypercapnia $\left(\mathrm{PaCO}_{2}>7 \mathrm{kPa}\right) 2$ weeks following resolution of respiratory acidosis $(\mathrm{pH}>7.30)$ secondary to an acute exacerbation of COPD. Non-invasive ventilation was titrated to treat nocturnal hypoventilation and patients were followed up for 1 years after discharge. Between group comparison of readmission and death were assessed in terms of baseline demographics, anthropometrics, lung function, gas exchange, quality of life and dyspnoea level.

Results 116 patients were enrolled and randomised to HOT $(n=59)$ or HOT-HMV $(n=57)$ with (mean \pm sd or median [IQR]) age $67 \pm 10$ years, BMI 22 [18-26] $\mathrm{kg} / \mathrm{m}^{2}, \mathrm{FEV}_{1} 0.6$ $\pm 0.2 \mathrm{~L}, \mathrm{PaCO}_{2} 59 \pm 7 \mathrm{mmHg}$, SRI-SS 46 \pm 15 , SGRQ-SS 74 [63-80], MRC dyspnoea score 5 [4-5]. Patients allocated HOT were less likely to be admitted with increasing BMI (25 \pm 5 vs $\left.22 \pm 6 \mathrm{~kg} / \mathrm{m}^{2} ; \mathrm{p}=0.044\right)$. Patients allocated to HOTHMV are were less likely to be admitted if they had higher $\mathrm{FEV}_{1}(0.66 \pm 0.24$ vs $0.54 \pm 0.20 \mathrm{~L} ; \mathrm{p}=0.042)$, lower levels of dyspnoea (MRC dyspnoea score $4 \pm 1.0$ vs $5 \pm 0.5 ; \mathrm{p}=0.002$ ) or higher levels of specific measures of quality of life (SGRQAC $85 \pm 13$ vs $92 \pm 7 ; p=0.015$ ) (Table 1 ). Baseline severity of respiratory failure did not predict 12 month outcome in either group.

Conclusion Factors influencing outcome in patients with COPD and persistent hypercapnia receiving HOT-HMV treatment were airways obstruction and level of dyspnoea. However, in the patients receiving HOT alone, BMI was the only factor. There was no between group difference in with the exception of a sub-scale of the SGRQ. Interestingly, the severity of respiratory failure at baseline does not influence risk of readmission or death within 12 months as the patients all demonstrated severe chronic respiratory failure

\section{S39 AN OUTREACH SERVICE FOR DOMICILIARY NON- INVASIVE VENTILATION (NIV) IMPROVES ACCESS FOR PATIENTS}

${ }^{1}$ SK Mansell, ${ }^{1} \mathrm{~S}$ Cutts, ${ }^{2} \mathrm{R}$ Kanakaraj, ${ }^{3} \mathrm{R}$ Jose, ${ }^{4} \mathrm{~A}$ Mackay, ${ }^{3} \mathrm{I}$ Moonsie, ${ }^{1} \mathrm{~S}$ Mandal. ${ }^{1}$ Royal Free London NHS Foundation Trust, London, UK; ${ }^{2}$ Whittington Hospital NHS Trust, London, UK; ${ }^{3}$ North Middlesex University Hospital NHS Trust, London, UK; ${ }^{4}$ University College London Hospital NHS Foundation Trust, London, UK

\subsection{6/thoraxjnl-2017-210983.45}

Introduction and Objectives Hypercapnic ventilatory failure is common and patients often present to hospital with decompensation. As well as requiring acute non-invasive ventilation (NIV), patients may require domiciliary NIV (D-NIV). Traditionally, inpatients requiring D-NIV awaited transfer to a hospital with a D-NIV service. Long wait times for transfer could result in; repeated decompensations, D-NIV services appearing inaccessible and alternative sub-optimal treatment options being considered. Increasing healthcare pressures mean newer models of care need to be considered to avoid delayed treatment. In May 2014 our D-NIV service implemented an outreach function. Inpatients referred for D-NIV were either visited at their base hospital, or attended as a day-case at our centre. Patients were assessed and, if appropriate, commenced on D-NIV. This study assessed the impact of our outreach service on accessibility to D-NIV services, hospital length of stay (LoS) and 90 day readmission rates (90R).

Methods Data were collected retrospectively pre-outreach and prospectively post-outreach service. Diagnosis, LoS and 90R were collected for all patients referred for D-NIV from five referring hospitals between January 2008 and April 2017. Historic patient databases of patients receiving acute NIV at site A were searched to compare pre-outreach to post-outreach service D-NIV referral rates. Based upon current evidence based practice, case note review of the historic database was undertaken to identify patients eligible for consideration of DNIV, but who were not referred.

Results Table 1. Demonstrates the impact of the outreach service. The study demonstrates a significant increase in referral rates following implementation of the outreach service. A clinically important reduction (21 days) in average LoS and subsequent decrease in bed day costs was observed. The average LoS cost per patient requiring D-NIV establishment pre-outreach was $£ 19,600$, compared to $£ 11200$ post-outreach service. A non-significant increase in $90 \mathrm{R}$ was observed.

Conclusion An outreach service appears to improve referral rates for D-NIV. There was a trend towards reduced LoS, potentially saving $£ 8400$ per patient. Factors contributing to increased 90R warrant further investigation. Our D-NIV outreach service appears to be an effective model of care, which has significantly increased patient accessibility to D-NIV and could be easily implemented in other services.

Abstract S39 Table 1 Referral rates, hospital LoS and 90 day readmission rates pre and post D-NIV outreach service

$\begin{array}{lll}\begin{array}{l}\text { Pre-outreach } \\ \text { service }\end{array} & \begin{array}{l}\text { Post- } \\ \text { outreach } \\ \text { service }\end{array} & \\ & \end{array}$

Patients eligible for D-NIV

Referral rates per acute NIV episodes at one referring site (Site A) (\%)

Further patients eligible for

consideration of D-NIV at Site A but

not referred (\%) COPD

COPD/OSA

$\mathrm{OHS}$

NMD

$10 / 669(1.5 \%) \quad 31 / 350$

$p<0.001$

$84 / 659(9.8 \%) \quad 1 / 319$

$\mathrm{p}<0.001$

$58.3 \%(49) \quad(0.3 \%)$

$4.7 \%(4) \quad 100 \%$

$30.9 \%(26) \quad$ (n1)

CWD

Patients at site A-E referred to D-NIV

service (n) Diagnosis\%(n): COPD

COPD/OSA

NMD

OHS

CWD

Other

$1.1 \%(1)$

$4.7 \%(4)$

$\begin{array}{ll}\begin{array}{l}\text { Inpatient } \\ \text { referral } \mathrm{n}=11\end{array} & \begin{array}{l}\text { Inpatient } \\ \text { referral }\end{array} \\ \text { Outpatient } & \mathrm{p}=0.431 \\ \text { referral } \mathrm{n}=7 & 26.4 \% \\ \text { Total } \mathrm{n}=17 & (18) \\ 38.9 \%(7) & 10.2 \%(7) \\ 0 \%(0) & 7.4 \%(5) \\ 16.7 \%(3) & 47 \%(32) \\ 38.9 \%(7) & 5.9 \%(4) \\ 5.6 \%(1) & 2.9 \%(2) \\ 0 \%(0) & \end{array}$

Patients referred to the service

$\begin{array}{lrl}\begin{array}{l}\text { Pre- } \\ \text { outreach } \\ \text { service }\end{array} & \begin{array}{l}\text { Post- } \\ \text { outreach }\end{array} & \\ \text { service } & \\ \begin{array}{l}\text { Site A-E } \\ \mathrm{n}=11\end{array} & \begin{array}{r}\text { Sites A-E } \\ \mathrm{n}=68\end{array} & \text { Mean diff } 20.7 \\ 49(49) & 28(26) & \begin{array}{l}(95 \% \mathrm{Cl}-14 \text { to } 56) \\ \mathrm{p}=0.167\end{array} \\ 10 \% & 30 \% & \mathrm{p}=0.264\end{array}$

$\mathrm{COPD}=$ chronic obstructive pulmonary disease, $\mathrm{OSA}=$ obstructive sleep apnoea, $\mathrm{NMD}=$ neuromuscular disease, $\mathrm{OHS}=$ obesity hypoventilation syndrome $\mathrm{CWD}=$ chest wall deformity. 